\title{
Aluno com deficiência intelectual no Ensino Médio: políticas educacionais inclusivas na rede estadual de Manaus/AM
}

Student with intellectual disability in High School: inclusive educational policies in the state network of Manaus/AM

Alumno con discapacidad intelectual em Secundaria: políticas educativas inclusivas en la red estatal de Manaus/AM

\section{Resumo}

O presente estudo teve como objetivo discorrer sobre as políticas educacionais inclusivas e como elas alcançam o aluno do ensino médio com deficiência intelectual em escolas da SEDUC/AM, tomando como referência sua implementação a partir das escolas investigadas. Metodologicamente, o estudo tem natureza qualitativa de análise documental, bibliográfica e de campo, com enfoque no método dialético, e para sua realização fizemos uso da entrevista semiestruturada. Inicialmente foram criadas categorias que, posteriormente, foram analisadas a partir das respostas extraídas no roteiro de entrevista utilizando a análise de conteúdo de Bardin (1977; 2011). Participaram do estudo os gestores institucionais que, dentro de suas funções, organizam, delegam e colaboram na implementação dos programas, projetos e ações, de competência federal ou estadual, nas escolas estaduais de ensino médio. Como principais resultados verificamos que as políticas educacionais, através de programas, projetos e ações, desenvolvidos para o público do Ensino Médio, em Manaus/AM, estão chegando às escolas para atender todos os alunos, o que não significa se estão alcançando o aluno com DI e promovendo mudanças significativas no seu processo de escolarização. O desafio da escola está no cumprimento dos princípios da inclusão evitando a manutenção da prática pedagógica homogênea, enquadrando o aluno com DI em procedimentos didáticos universais, desconsiderando as diferenças. Através do Programa Escola Acessível (PEA) está sendo possível reestruturar as escolas que aderem ao PEA em infraestrutura, com recursos disponibilizados às contempladas pelo Programa Implantação de Salas de Recursos Multifuncionais (SRM) e o Atendimento Educacional Especializado (AEE) aos alunos com DI ou outras deficiências.

Palavras-chave: Educação; Ensino; Deficiência intelectual; Amazonas.

\begin{abstract}
The present study aimed to discuss inclusive educational policies and how they reach high school students with intellectual disabilities in SEDUC/AM schools, taking as a reference their implementation from the investigated schools. Methodologically, the study has a qualitative nature of documental, bibliographic and field analysis, focusing on the dialectical method, and for its accomplishment we used the semi-structured interview. Initially, categories were created that were later analyzed from the answers extracted from the interview script using Bardin's content analysis (1977; 2011). Institutional managers who, within their functions, organize, delegate and collaborate in the implementation of programs, projects and actions, of federal or state competence, in state high schools participated in the study. As main results, we verified that educational policies, through programs, projects and actions, developed for the high school public, in Manaus/AM, are reaching schools to serve all students, which does not mean if they are reaching the student with DI and promoting significant changes in their schooling process. The school's challenge lies in complying with the principles of inclusion, avoiding the maintenance of homogeneous pedagogical practice, framing the student with ID in universal didactic procedures, disregarding differences. Through the Accessible School
\end{abstract}


Program (PEA) it is possible to restructure the schools that adhere to the PEA in terms of infrastructure, with resources made available to those covered by the Program for the Implementation of Multifunctional Resource Rooms (SRM) and the Specialized Educational Assistance (AEE) for students with ID or other deficiencies.

Keywords: Education; Teaching; Intellectual disability; Amazonas.

\section{Resumen}

El presente estudio tuvo como objetivo discutir las políticas educativas inclusivas y cómo llegan a los estudiantes de secundaria con discapacidad intelectual en las escuelas de la SEDUC/AM, tomando como referencia su implementación a partir de las escuelas investigadas. Metodológicamente, el estudio tiene carácter cualitativo de análisis documental, bibliográfico y de campo, centrándose en el método dialéctico, y para su realización se utilizó la entrevista semiestructurada. Inicialmente se crearon categorías que luego fueron analizadas a partir de las respuestas extraídas del guión de la entrevista mediante el análisis de contenido de Bardin (1977; 2011). Participaron del estudio los directivos institucionales que, dentro de sus funciones, organizan, delegan y colaboran en la ejecución de programas, proyectos y acciones, de competencia federal o estatal, en las escuelas secundarias estatales. Como principales resultados, verificamos que las políticas educativas, a través de programas, proyectos y acciones, desarrolladas para el público de la escuela secundaria, en Manaus/AM, están llegando a las escuelas para atender a todos los estudiantes, lo que no significa que estén llegando al estudiante con DI y promoviendo cambios significativos en su proceso de escolarización. El desafío de la escuela está en cumplir con los principios de inclusión, evitando el mantenimiento de una práctica pedagógica homogénea, enmarcando al alumno con DI en procedimientos didácticos universales, sin tener en cuenta las diferencias. A través del Programa Escuela Accesible (PEA) es posible reestructurar las escuelas adheridas al PEA en materia de infraestructura, con recursos puestos a disposición de los amparados por el Programa de Implementación de Salas de Recursos Multifuncionales (SRM) y la Atención Educativa Especializada (AEE) para alumnos con DNI u otras deficiencias.

Palabras clave: Educación; Enseñanza; Discapacidad intelectual; Amazonas.

\section{Introdução}

O presente estudo está apoiado sobre as políticas públicas educacionais no contexto inclusivo para os alunos com deficiências intelectual (DI) no ensino médio regular nas escolas da rede estadual de ensino na cidade de Manaus/AM. Seu objeto de estudo, alicerçado na legislação nacional e estadual, é sobre a implementação das políticas inclusivas, através dos programas, projetos, ações e serviços, que estão alcançando o aluno com deficiência intelectual nas escolas de ensino médio da SEDUC/AM.

A Lei de Diretrizes e Bases da Educação Nacional (Brasil, 1996) reserva um capítulo para a educação especial. No artigo 59, define e assegura currículo, métodos, recursos e organização específicos para atender às suas necessidades o público dessa modalidade. No início do século seguinte, com a implementação das Diretrizes Nacionais para a Educação Especial na Educação Básica (Brasil, 2001), os sistemas de ensino, por força de lei, deveriam matricular todos os alunos com Deficiência nas escolas comuns, de modo a garantirem o acesso e a permanência desses alunos no ambiente escolar, bem como desenvolver o potencial educativo dessas pessoas.

O direito de todos à educação está evidenciado nos princípios constitucionais e somente se efetivará em um sistema educacional inclusivo com medidas que ofereçam recursos de acessibilidade na eliminação de barreiras, considerando que as escolas comuns com orientação inclusiva são os meios mais eficazes no combate as atitudes discriminatórias e obtenção de uma real educação para todos (UNESCO, 1990; 1994; ONU, 1999; 2006; Brasil, 2008; 2015).

Em 2017, com a publicação da Lei do Novo Ensino Médio, Lei n ${ }^{\circ}$ 13.415, que alterou a LDBEN/1996, em suas Diretrizes Curriculares Nacionais, Resolução nº 3/2018, artigo 17, § 6º , ordena que o ensino médio deve assegurar sua função normativa para todos os estudantes, devendo ser observadas, para a educação especial, as respectivas diretrizes e normas nacionais.

Em vista disso, o interesse em pesquisar sobre a temática DI ocorreu mediante experiência profissional como pedagoga em uma escola de ensino médio da rede pública estadual que, a partir do ano de 2009, com o advento da educação especial na perspectiva inclusiva já em curso, me oportunizou vivenciar e participar do fazer pedagógico no processo de 
ensino-aprendizagem de alunos da educação especial que chegavam à escola, dentre os quais o aluno com Deficiência Intelectual.

Conforme destacam Dias e Oliveira (2012), de alguma forma, os alunos com DI estão influenciando, com a evidência de seus progressos, mudanças nas concepções acerca da deficiência e de si mesmos. O fato é que este acontecimento desencadeou preocupação com a escolarização desses alunos, uma vez que aflorou no ambiente escolar questionamentos sobre como se daria o acesso e a permanência desses alunos na escola de modo a não ser colocada nenhuma barreira e o acolhimento pedagógico fosse igual ao oferecido aos alunos sem deficiência.

A crescente demanda de matrículas para alunos com DI nos últimos anos na escola, provocou uma certa inquietude entre os professores pela inexperiência e o desconhecimento de práticas pedagógicas que favorecessem a aprendizagem dos alunos com DI, recém-chegados. Implantado o desafio profissional em planejar e replanejar estratégias de ensino para atender esse grupo de alunos em igualdade de condições de aprendizagem aos alunos sem deficiência, constatou-se não somente a necessidade de conhecermos práticas didático-pedagógicas inovadoras e inclusivas de modo a darmos suporte pedagógico ao professor da sala de aula comum, bem como percorrer pelas Políticas Educacionais Inclusivas que estão sendo implementadas pela SEDUC/AM nas escolas da rede pública estadual, na cidade de Manaus/AM, em especial, no atendimento do aluno com DI no Ensino Médio.

A educação inclusiva constitui um paradigma educacional fundamentado na concepção de direitos humanos (Brasil, 2008, p. 10) e está alicerçada pela legislação brasileira que é abundante, de qualidade, mas com pouca aplicabilidade na garantia dos direitos a escolarização com equidade dos alunos da educação especial, especificamente os com DI, que fazem parte do processo de superação da exclusão no ambiente escolar. Logo, o presente estudo apresenta o panorama atual de Manaus/AM quanto às políticas educacionais inclusivas implementadas nas escolas de ensino médio regular para atender ao aluno com DI. São apresentados os resultados das entrevistas realizadas, além da legislação e documentos oficiais que versam sobre os direitos do aluno com DI no Ensino Médio.

\section{Metodologia}

A pesquisa foi realizada na SEDUC/AM no município de Manaus: no Departamento de Política e Programas Educacionais (DEPPE), na Coordenadoria de Ensino Médio (CEM) e na Coordenadoria de Educação Especial (CEE); na Coordenadoria Distrital de Educação (CDE) 3 (zona Centro-Oeste) e na Coordenadoria Distrital de Educação (CDE) 5 (zona Leste), sendo: 2 (duas) escolas de cada CDE, 1 (uma) escola equipada com Sala de Recursos Multifucionais (SRM) e o Atendimento Educacional Especializado (AEE) e 1 (uma) sem a estrutura supracitada, totalizando 4 (quatro) escolas.

A escolha dessas escolas deu-se pelo fato de serem escolas que oferecem o ensino médio regular, funcionam em turnos, apresentam em seu quadro estudantil, alunos com deficiência intelectual matriculados e frequentando e por estarem localizadas em área estratégica da cidade de Manaus/AM. As zonas Centro-Oeste e Leste, em 2018, registraram o maior número de matrículas de aluno com DI no ensino médio, sendo 24 na CDE3 e 61 na CDE5.

Foram realizadas entrevistas semiestruturadas com os sujeitos selecionados. Para a escolha das escolas foi solicitado à Gerência de Estatística da SEDUC/AM, via ofício, o mapa geral de matrículas das escolas da capital, evidenciando a matrícula dos alunos com deficiência no ensino médio e o tipo de deficiência. A partir dessa informação a escolha das escolas teve como critério de inclusão: oferta de ensino médio regular; funcionamento por turno; alunos com deficiência intelectual matriculados e frequentando o ensino médio regular; e que das duas escolas selecionadas por Coordenadoria, uma oferecesse o serviço de AEE em SRM e a outra não fosse equipada por esse serviço e recurso. Foram realizadas visitas técnicas entre os meses de janeiro a março de 2020. 
No estudo ocorreu a pesquisa de campo com entrevistas realizadas com a direção do DEPPE e a coordenação da CEE, lotados na SEDUC/Sede; os coordenadores distritais da CDE 3 e 5 e os gestores das quatro escolas estaduais de ensino médio regular, já selecionadas, no município de Manaus/AM. A coordenação da CEM foi contatada em diversos momentos para agendamento e realização da entrevista, mas não se obteve sucesso, apesar da concordância em participar da pesquisa, com assinatura no TCLE.

Foi realizado contato informal via telefone para o agendamento das visitas e entrevistas. Após agendamento, realizouse as visitas para realização das entrevistas. Algumas foram gravadas, outras respondidas manualmente e outras respondidas posteriormente via e-mail. Nas visitas, além das entrevistas, foram apresentadas as SRM e material didático/pedagógico utilizado no atendimento do aluno com DI, nas escolas com essa estrutura. Após a suspensão das atividades presenciais devido a pandemia provocada pelo vírus que propagou a doença COVID-19, o contato com os entrevistados foi realizado por e-mail ou aplicativos de comunicação.

Para análise do material da pesquisa foi utilizada a análise de conteúdo sob a definição de Bardin (1977, p. 42). Entre as principais técnicas apontadas para análise de conteúdo, selecionados como proposta para o nosso estudo a técnica categorial.

Dessa forma, utilizamos como eixos temáticos da análise e interpretação de dados: i) Aporte teóricos evidenciando as políticas públicas educacionais nacionais relacionadas ao Ensino Médio, considerando aspectos da educação inclusiva; ii) Subsídios jurídicos que sustentam a escola pública inclusiva para aluno com Deficiência Intelectual no ensino médio; e, iii) Implementação de políticas educacionais inclusivas, em escolas de ensino médio regular da SEDUC/AM, na cidade Manaus, para alunos com Deficiência Intelectual.

O material coletado em campo foi organizado e registrado em formulário previamente elaborado, sendo para a administração da SEDUC, para as coordenadorias e para os gestores de escolas. Para a elaboração de quadros e tabelas dos dados coletados utilizou-se os recursos dos programas Microsoft Excel e Microsoft Word com o objetivo de obter as informações diretas e necessárias a elaboração de análises, discussões e resultado da pesquisa.

\section{Resultados e Discussão}

Neste estudo, com embasamento na legislação vigente da educação, tomamos por base as garantias à educação das pessoas com Deficiência Intelectual no Ensino Médio regular, observando como o Estado do Amazonas, representado pela SEDUC/AM, se comporta perante a evolução da legislação nacional assegurando, através das políticas educacionais inclusivas, a escolarização dos alunos com DI onde, o acesso a essa escolarização perpetue todos os direitos ligados à educação desse público.

\subsection{Caracterizando a SEDUC/AM}

O Estado do Amazonas, com grande extensão territorial, é parte de um ecossistema complexo e diversificado, principalmente por considerar questões sociais, culturais, ecológica e econômica. É uma região exuberante, com extensas riquezas e belezas naturais, mas com pobreza e miséria social (Gutberlet, 2002 p. 157). Essas realidades antagônicas refletem de forma positiva ou negativa nas políticas públicas do acesso à educação, no direito humano e fundamental de segunda dimensão, ou seja, nos direitos sociais, econômicos e culturais, positivados na legislação nacional e estadual.

No cenário da educação das escolas públicas do Estado do Amazonas, direcionamos nosso estudo às escolas estaduais de ensino médio regular, por turno, na cidade de Manaus, administradas pela SEDUC/AM.

No sítio eletrônico da SEDUC/AM, consta no histórico da Secretaria de Educação que a instituição foi criada no ano de 1946 pela Lei nº 1.596, cuja denominação escolhida na época foi Diretoria Geral do Departamento de Educação e Cultura. 
A partir de sua criação passou por outras denominações. No ano de 2000, recebeu o nome de Secretaria de Estado de Educação e Qualidade do Ensino, permanecendo com esse nome até outubro de 2019 (Seduc, 2020).

A denominação atual da Secretaria de Educação, ocorreu em 2019, na Reforma Administrativa do governador Wilson Lima, através da Lei Delegada ${ }^{\circ} 122$ de 15 de outubro de 2019, que dentre as mudanças administrativas, fez a fusão da Secretaria de Educação (SEDUC) com a Secretaria de Esporte (SEJEL), transformando na Secretaria de Estado de Educação e Desporto (Amazonas, 2019c).

Vale ressaltar que uma das justificativas do governador Wilson Lima para a fusão da Secretaria de Educação e Secretaria de Esporte, constante na Lei Delegada das mudanças administrativas, foi visando melhoria dos indicadores institucionais, exemplificado a melhoria da educação para o ensino médio que pela primeira vez não havia alcançado a meta projetada para o IDEB/2017 (Amazonas, 2019b).

A SEDUC/AM, na alteração da sua estrutura organizacional, para desenvolver as atividades-fim instituiu, com base na Lei Delegada n 3.642 de 26 de julho de 2011, as atribuições do Departamento de Políticas e Programas Educacionais (DEPPE), cuja responsabilidade está em coordenar as políticas públicas para a educação básica no Estado do Amazonas. Esse Departamento, atualmente, se subdivide em quatro gerências, incluindo a Gerência de Ensino Regular (GER), que, dentre as suas responsabilidades, desenvolve políticas educacionais para o Ensino Médio; e, a Gerência do Atendimento Educacional Específico e da Diversidade (GAEED) que, dentre suas competências, tem a responsabilidade em promover ações para o fortalecimento, expansão e melhoria da educação estadual (Amazonas, 2019d).

$\mathrm{Na}$ organização estrutural, a GER se divide em 4 (quatro) coordenadorias das quais a Coordenadoria de Ensino Médio (CEM); e a GAEED, também com 4 (quatro) coordenadorias, das quais referenciamos a Coordenadoria de Educação Especial (CEE), que tem como função o atendimento do público da Educação Especial (Seduc, 2020).

A SEDUC/AM, em Manaus, apresenta o quantitativo de 232 escolas, distribuídas entre as 7 (sete) Coordenadorias Distritais de Educação (CDE). Do total de escolas na capital, 111 oferecem o Ensino Médio regular, por turno (Seduc, 2020).

Essas CDE fazem parte na reestruturação organizacional da SEDUC/AM, realizada em 2011, cujo objetivo estava em descentralizar o apoio à gestão das unidades escolares, na época, coordenado pelo Departamento de Gestão Escolar (DEGESC), na Sede. As CDE, localizadas por zona geográfica em Manaus, têm dentre suas atribuições coordenar, implementar, assessorar e acompanhar as ações administrativas e pedagógicas das escolas sob suas responsabilidades (Amazonas, 2011).

Em relação as matrículas dos alunos com DI no Ensino Médio em escolas estaduais, todas oferecem vagas utilizando o Sistema SIGEAM instalado na rede SEDUC/AM. Nas escolas em Manaus, das por turno às de Tempo Integral, a matrícula de alunos com DI ou outra deficiência, em classes comuns do ensino regular, é efetivada em obediência à regra constitucional, inclusive com direito ao atendimento educacional especializado.

Dito isso, o MEC, através de Nota Técnica ${ }^{\circ}$ 20/2015, faz referência a dispositivos legais que dispõem sobre a educação como direito de todos em sistema educacional inclusivo e afirma que será penalizado com multa de 03 (três) a 20 (vinte) salários-mínimos o gestor escolar, ou autoridade competente, que recusar a matrícula de aluno com qualquer tipo de deficiência (Brasil, 2015).

Essa determinação do MEC em penalizar o gestor escolar, com multa, se recusar matrícula de aluno com deficiência, com a publicação da LBI em 2015, artigo 98, inciso I, passou a ser crime punível com reclusão de 2 a 5 anos, mais multa (Brasil, 2015).

Traçando um comparativo da matrícula de alunos com DI, em salas comuns das escolas estaduais, por turnos, em Manaus, no ano de 2018, se registrou matrícula de 1.365 alunos com DI, no mesmo ano, apenas 213 alunos com DI, aparecem 
matriculados no ensino médio regular, em escolas por turno. Em percentuais, isso representa apenas 15,60\% de alunos com DI matriculados e frequentando as classes comuns do ensino médio nas escolas estaduais, em Manaus.

\subsection{SEDUC/AM alinhando com a educação inclusiva}

A SEDUC/AM, para a concretização das diretrizes trazidas pela PNEEPEI/2008 segue orientações estabelecidas na legislação nacional e estadual. No Amazonas, o documento normativo de instrução às instituições escolares no atendimento dos alunos com DI é a Resolução ${ }^{\circ} 138$ de 2012 do CEE/AM, em vigência, editada para garantir o desenvolvimento de programas, projetos e ações no atendimento da escolarização do público alvo da educação especial em classes comuns nas escolas estaduais.

A Resolução supracitada regulamenta regras nacionais e segue orientações da PNEEPEI de 2008 e suas diretrizes. Dispõe em seu artigo $4^{\circ}$ e incisos sobre quem são os alunos da educação especial, especificando no inciso I a Deficiência Intelectual. Na alínea "a" do mesmo artigo define a pessoa com deficiência como sendo "Aquela que tem impedimentos a longo prazo, de natureza física, intelectual, sensorial ou múltipla, que, em interação com diversas barreiras, podem ter restringida sua participação plena e efetiva na escola e na sociedade."

O artigo 20 dessa Resolução, relaciona procedimentos para o atendimento educacional especializado e acessibilidade dos alunos da educação especial, no caso, os com DI, bem como a formação de professores em estratégias didáticas e pedagógicas na rede estadual de ensino.

Quanto ao funcionamento das Salas de Recursos Multifuncionais (SRM), o professor da SEDUC/AM deverá ter formação em nível superior e formação específica na área de Educação Especial em cursos com carga horária mínima de 80 horas. A SEDUC/AM ainda mantém escolas e serviços de atendimentos específicos instalados em Manaus que servem de suporte no atendimento de alunos da educação especial. Nesse tipo de escola, os alunos com deficiência intelectual são atendidos em duas escolas, uma que oferece o ensino fundamental e outra para alunos maiores de 15 anos, através de oficinas pedagógicas em atividades laborativas. Disponibiliza, também, na Escola Estadual Mayara Redman Abdel Aziz, 3 (três) Centros de Formação e Apoio Pedagógico Específico e 1 (um) Núcleo para Alta Habilidade/Superdotação (Amazonas, 2019).

Dentre os serviços pedagógicos diferenciados realizados pela SEDUC/AM, como formas alternativas que garantem o acesso escolar, são destacados como atendimento ao aluno os serviços em Classe Hospitalar e Domiciliar, o Auxiliar de Vida Escolar, o do Professor Intérprete de Libras e o Psicossocial nas escolas (Amazonas, 2019).

Em relação as SRM implantadas nas escolas comuns, dos 62 municípios do Amazonas, 56 apresentam 165 SRM instaladas e em funcionamento, sendo 68 em Manaus (capital) e 97 distribuidas nas cinco mesorregião, assegurando metodologias diferenciadas, com atendimento aos alunos que necessitam do AEE (Amazonas, 2019).

Na PNEEPEI de 2008 e legislação específica, as Salas de Recursos Multifuncionais são mais completas em serviços e equipamentos de modo a proporcionar a complementação curricular específica nos espaços do AEE. São serviços pedagógicos desenvolvidos para suplementar, no caso da superdotação e complementar no caso de deficiência e TGD.

Nos argumentos de Bueno (2016, p. 9), a SRM é o Programa que pode ser considerado "o carro chefe da política de educação especial na perspectiva inclusiva, na medida em que foi processo pelo qual o Ministério da Educação implementou apoio especializado a alunos da educação especial incluídos nos estabelecimentos de ensino regular da educação básica."

Dessa forma, buscando reforços em estudos que investigaram sobre a educação inclusiva em estados da região Norte, com destaque ao Amazonas, Dambros e Mori (2015. p.7), constataram que por dependência administrativa, a municipal sobressai em relação a estadual, no quantitativo de matrículas em classes comuns de alunos com deficiência/transtorno, o que se justifica por concentrar a maioria dos alunos da educação infantil e do ensino fundamental nas escolas municipais. O AEE 
apresenta aspecto significativo como suporte nesse processo, mesmo com número insuficiente de SRM implantadas nas escolas.

Apesar das pesquisas mencionarem o número insuficiente de SRM para atender a demanda de alunos da educação especial em Manaus, existe um grau de positividade em razão do fortalecimento na realização da parceria entre a gestão escolar municipal e a estadual, considerando que o AEE, em regra do Decreto $\mathrm{n}^{\circ} 7.611$ de 2011, deve ser oferecido na rede pública de ensino regular, em qualquer dependência administrativa dos sistemas públicos de ensino e instituições sem fins lucrativos (BRASIL, 2011).

Posto isto, e utilizando do embasamento teórico e jurídico nos resultados e discussão, será apresentada, na seção seguinte e nas suas respectivas subseções, a percepção dos gestores institucionais entrevistados cujas indagações estão relacionadas às políticas públicas de educação implementadas pela SEDUC/AM, nas escolas de ensino médio regular, na cidade de Manaus que, através de programas, projetos, ações e serviços, possam atender ao modelo educacional inclusivo, especificamente para alunos com Deficiência Intelectual.

\subsection{Como os gestores institucionais percebem o aluno com DI no ensino médio}

A intenção nesta seção é apresentar os resultados e análises, cuja organização mostra os relatos dos gestores institucionais entrevistados de modo a apurar suas percepções acerca das políticas educacionais inclusivas implementadas para atender alunos com DI no ensino médio, em escolas de Manaus/AM.

Os profissionais selecionados para as entrevistas são gestores em cargos comissionados, considerando os vinculados hierarquicamente à Secretaria Executiva da Capital e à Secretaria Executiva Adjunta Pedagógica na SEDUC/AM, da direção do DEPPE à gestão escolar. Para uma melhor compreensão conceitual desse tipo de gestão pública gerencial nos apropriamos das palavras de Rek (2015) quando nos diz que a gestão gerencial é o modelo de gestão que

visa à obtenção de bons resultados [...] pela eficiência, simplificação de processos, economicidade, a prestação de serviços públicos de qualidade, [...], atentando-se principalmente aos anseios da coletividade e, essencialmente, com foco no cidadão, o qual é o verdadeiro proprietário da 'res pública' (Rek, 2015).

A gestão gerencial na Administração Pública foi ilustrada com a publicação da EC nº 19/1998, quando acrescentou o Princípio da Eficiência ao conjunto de princípios contidos no artigo 37 da CRFB/1988 que trata da Administração Pública de qualquer dos Poderes: União, Estados, Distrito Federal e Municípios, positivando, dessa forma, a Eficiência em todos os atos e procedimentos administrativos no serviço público, no caso, na educação.

A caracterização dos profissionais no quadro supracitado foi extraída das informações colhidas no Roteiro de Entrevista, não sendo disponibilizado, portanto, a confirmação dos dados em documentos oficiais.

As entrevistas propuseram temáticas direcionadas às políticas educacionais inclusivas para o Ensino Médio desenvolvidas pela SEDUC/AM, as quais estão relacionadas: a) aos programas, projetos, ações e serviços pedagógicos inclusivos; b) orientações repassadas sobre recursos pedagógicos, adaptações, acessibilidade e formação continuada; e, c) a inclusão escolar do aluno com DI no Ensino Médio. O protocolo de entrevista se estruturou em categorias transversalizando os relatos para a análise crítica, as quais sinalizam serem as mais importantes para a reflexão sobre este estudo.

A seguir apresentaremos as categorias em ordem de modo a facilitar e auxiliar numa crítica reflexiva do objeto de estudo apoiado na literatura e legislação apresentadas. Os agentes participantes da pesquisa estão denominados por siglas no gerenciamento do quadro funcional da SEDUC/AM: GS1 e GS2 (Sede); GC1 e GC2 (Coordenadorias); e GE1, GE2, GE3, GE4 (Escola). 


\subsubsection{Programas, projetos, ações e serviços pedagógicos inclusivos}

No atendimento escolar na rede estadual de ensino para cada ano letivo, a SEDUC/AM sistematiza o planejamento de insumos que são oferecidos aos alunos, professores e escolas estaduais de todas as etapas da educação básica. Portanto, é de competência dessa Secretaria propor e executar projetos, programas, ações e serviços que garantam o cumprimento da política educacional destinada a todos os alunos sem distinção, considerando a promoção de recursos humanos; materiais didáticos, pedagógicos e tecnológicos; mobiliários; e infraestrutura, enfim, de modo a suprir todas as necessidades do sistema estadual de ensino.

Quando indagado aos profissionais entrevistados sobre as políticas educacionais implementadas pela SEDUC/AM, no processo de inclusão dos estudantes com Deficiência Intelectual nas escolas comuns de ensino médio, os Profissionais GS1 e GS2, lotados na sede da Secretaria de Educação, em órgãos de atividades finalísticas, direcionaram suas falas aos programas e projetos que atendem alunos do ensino médio, não especificamente alunos com DI, mas contemplando todos os alunos dentro da unidade escolar na qual estudam.

A maioria dos programas citados pelos agentes entrevistados são de competência federal, com financiamento através do Fundo Nacional de Desenvolvimento da Educação (FNDE). Atualmente, esse Fundo participa da maior parte das políticas educacionais desenvolvidas pelo MEC, principalmente as consideradas descentralizadas. Suas ações de assistência financeira aos entes públicos (Estados, Distrito Federal e Municípios) são classificadas em direta, quando a execução da política é centralizada no FNDE (PNLD); em automática, onde o recurso financeiro tem caráter suplementar (PDDE); e, por fim, assistência financeira voluntária, nesta o MEC que prioriza (Brasil, 2020, p. 12).

Os profissionais entrevistados GS1 e GS2 relacionam vários programas e projetos federais desenvolvidos pela SEDUC/AM ou em parceria para atender alunos do Ensino Médio que somados às informações colhidas em outras fontes. Na fala dos profissionais GS1 e GS2, respectivamente, é mencionado que a SEDUC/AM utiliza mecanismo como relatórios, metas e avaliações para mensurar o alcance da política educacional nas unidades escolares; e com a implementação do Programa Escola Acessível, criado pelo MEC e desenvolvido pela SEDUC/AM, o repasse de verbas às unidades escolares está possibilitando a estruturação física, pedagógica, tecnológica e humana para o atendimento dos alunos da educação especial no processo de inclusão escolar.

O Programa Escola Acessível (PEA) mencionado na entrevista, foi instituído no ano de 2007, através do Decreto no 6.094, sendo integrado ao PDE em 2008. Este, investia na infraestrutura das escolas, abordando sobre a acessibilidade das edificações escolares, a formação docente e a implantação das SRM. Sobre o PEA, seu propósito é injetar verba diretamente nas unidades escolares, através do PDDE Acessibilidade (Brasil, 2011).

O PEA está disponível para atender todas as escolas brasileiras que apresentem interesse em aderir ao Programa indicando suas necessidades estruturais, no campo físico, pedagógico, tecnológico e humano. Os gestores escolares devem ser incentivados e orientados pelas Secretarias de Educação em buscarem, junto ao governo federal, esses recursos financeiros e assim adequarem as escolas em ambientes mais acessível aos estudantes.

O Amazonas, em 2018, foi o estado da federação que apresentou o menor número de escolas consideradas acessíveis, ou seja, apenas o percentual de 7,6\%, enquanto o Distrito Federal apresentou o maior número com o percentual de 73,3\%, onde a média nacional equivale a 25,3\% de escolas com acessibilidade (Brasil, 2019).

Essa informação demonstra que, apesar do Programa Escola Acessível existir desde 2007, e ser citado pelo entrevistado GS2 como política de acessibilidade sendo implementada nas escolas de ensino médio em Manaus/AM, pelos dados de matrículas do MEC muitas escolas ainda carecem de recursos para adequação de seus ambientes de modo a atender os alunos com deficiência ou mobilidade reduzida. 
Os profissionais entrevistados GC1 e GC2 destacam sobre a importância de AEE para alunos com DI, mesmo reconhecendo que esse atendimento especializado tem oferta mínima, considerando a necessidade das escolas de ensino médio. Mencionam sobre a necessidade de inovar o fazer pedagógico para o atendimento desse público, seja a escola equipada ou não com a SRM e oferta de AEE.

Em outro argumento, destacam o serviço profissional de apoio, conhecido como "Auxiliar de Vida Escolar", evidenciando o despreparo desse profissional que é enviado para a escola e da necessidade tanto desse profissional quanto dos demais professores que atuam na sala de aula comum, da formação continuada e específica de modo a assegurar o atendimento do aluno com DI dentro das normas de inclusão (Brasil, 2010).

Para a mesma temática, os profissionais entrevistados GE1, GE2, GE3, GE4, que são gestores e respondem pelo gerenciamento escolar, em suas análises, os programas, projetos e ações pedagógicos devem estar institucionalizados no Projeto Político Pedagógico da escola. Os argumentos desses agentes mostram a necessidade da existência do PPP da escola. Conforme a Resolução n 4/2009 CNE/CEB que institui as Diretrizes Operacionais do AEE, referenciadas na Nota Técnica $n^{\circ}$ 04/2014 do MEC, diz que no PPP deve institucionalizar a oferta do AEE no ensino regular constando sobre: a elaboração e execução do plano de AEE pelos professores que atuam na SRM em articulação com os demais professores do ensino regular; a matrícula de alunos no AEE; cronograma de atendimento aos alunos; outros profissionais da educação e outros que atuem no apoio; e organização do tipo e do número de atendimentos aos alunos da SRM (Brasil, 2014).

Cabe ressaltar que esse detalhamento no PPP da escola, considerando que a existência da SRM na unidade escolar possa otimizar o espaço físico adequado de modo a garantir a acessibilidade que potencializa pedagogicamente os estudantes, independentemente onde o aluno com DI está matriculado, uma vez que esse estudante tem direito ao AEE a ser ofertado de forma complementar a sua escolarização, em turno oposto à sua escolaridade na classe comum, em qualquer unidade escolar que tenha SRM, de qualquer dependência administrativa (Brasil, 2011).

Contudo, embora o PPP tenha sido referenciado pelos profissionais entrevistados que atuam no gerenciamento das unidades escolares, como o documento norteador que registra todas as ações desenvolvidas pela escola, não foi possível o acesso a esse documento sob a justificativa de estar sendo reestruturado e, portanto, indisponível para estudo/análise.

Ainda sobre a fala dos profissionais que gerenciam as unidades escolares fica evidenciado a forma positiva e negativa como se expressam, quando comparado as respostas dos gestores das escolas que possuem SRM implantadas e funcionando, portanto, com AEE, e as dos gestores das escolas que não têm esse recurso para o atendimento do aluno, no caso o aluno com DI. A seguir o recorte dos relatos:

Sendo um serviço de fundamental importância na política de inclusão, o AEE aparece constantemente nas falas dos profissionais entrevistados. Na fala dos gestores GE1 e GE3 de escolas que oferecem o AEE, os discursos fluem com mais otimismo em relação a funcionalidade desse atendimento especializado na complementação da escolarização do aluno com DI. Já para os gestores GE2 e GE4 das escolas que não estão vinculadas ao Programa de Implantação das Salas Multifuncionais do MEC, portanto, não oferecem o AEE, as falas refletem a insatisfação em relação a desestruturação da escola para esse fim, ficando explícito a reivindicação à SEDUC pela necessidade desse serviço de apoio a escolarização dos alunos.

Independentemente da quantidade de SRM, implantadas e funcionando em escolas de Manaus/AM, o estudante com DI tem direito ao serviço de AEE o qual não pode se confundir com atividade de reforço escolar. Esta, como atividade extracurricular deve fazer parte do PPP da escola e ser oferecida a todos os estudantes que dela se beneficiem e pode ser oferecida em paralelo as atividades trabalhadas em sala de aula comum e no AEE, caso o estudante faça parte do público da educação especial (Brasil, 2011).

Em relação as Políticas Educacionais do Estado do Amazonas, no ano de 2016, o Instituto UNIBANCO realizou um estudo, que resultou numa mostra com 33 (trinta e três) programas e projetos identificados e desenvolvidos pela SEDUC/AM 
no atendimento de todas as etapas da educação básica, sendo de competência federal, desenvolvido pelo MEC ou em parceria com o referido Ministério, bem como de programas e projetos de competência estadual desenvolvidos exclusivamente pela SEDUC/AM.

No contexto, a implementação dos programas, projetos e ações para atender aos alunos do Ensino Médio citados no estudo do Instituto UNIBANCO, na Mensagem Governamental e nas respostas dos profissionais entrevistados GS1 e GS2, independe se o aluno tem ou não deficiência ou algum tipo de transtorno, a oferta vem para atender a todos embora possa existir critérios de seleção que dificulte o acesso do aluno com DI como, por exemplo, o maior desempenho em pontuação nos bimestres letivos. Outro ponto a destacar é que a maioria dos programas e projetos são de âmbito federal executados pela SEDUC/AM.

O que se pode concluir em relação a participação do aluno com DI no processo escolar, através dos programas, projetos, ações e serviços organizados pela SEDUC/AM e viabilizados pelas escolas ou em projetos e ações criados e desenvolvidos pela própria escola, depende da participação da comunidade escolar, principalmente do empenho da gestão escolar em cumprir regras da inclusão a partir do protocolo de matrícula do aluno e, de modo contínuo, na trajetória de sua escolarização na escola.

\subsection{Recursos Pedagógicos, Adaptações, Acessibilidade e Formação continuada}

A SEDUC/AM, através de sua gestão institucional pedagógica, justifica que na trajetória da educação especial na perspectiva inclusiva, tem atuado na busca de um crescimento significativo através da implementação de programas e ações político-educacionais na sua rede de ensino.

$\mathrm{Na}$ entrevista, buscou-se dos profissionais, dentro de suas funções, saber sobre as orientações recebidas e repassadas, hierarquicamente, em relação a recursos pedagógicos, adaptações, acessibilidade e formação continuada para o acolhimento dos alunos com Deficiência Intelectual no ambiente escolar. Na fala dos profissionais entrevistados GS1 e GS2, as escolas de ensino médio de modo a atender a demanda de alunos com deficiência, em específico o aluno com Deficiência Intelectual, oferecem serviços de apoio à inclusão, dando subsídio pedagógico ao professor da sala de aula comum que em parceria com o professor da SRM, através de AEE, proporcionam o atendimento ao aluno incluído.

Ainda no discurso dos profissionais GS1 e GS2, as orientações para as coordenadorias distritais e sucessivamente às escolas, partem hierarquicamente da Coordenação de Educação Especial que dá assessoramento, inclusive na org anização da formação continuada e específica aos professores do AEE e das classes comuns. Na fala dos profissionais GS1, GS2, GC1 e GC2, que ocupam função de diretoria e coordenadoria, a SEDUC/AM vem cumprindo de modo satisfatório o que determina a Resolução nº 138/2012 do CEE/AM, embora seja mencionado que têm escolas apresentando estrutura física inadequada para atender a acessibilidade dos alunos com Deficiência.

Argumenta, ainda, esse grupo de profissionais entrevistados, que os recursos pedagógicos, tecnológicos ou adaptação espacial de modo a eliminar as barreiras e adequar a escola, provém de recursos financeiros injetados pelo Fundo Nacional de Desenvolvimento da Educação (FNDE) através da adesão das escolas aos Programas criados pelo MEC. O FNDE é uma autarquia federal criada em 1968, cuja responsabilidade é pela execução de políticas educacionais do MEC.

As escolas têm a Associação de Pais, Mestres e Comunitários (APMC), unidade executora determinada pelo MEC que as representam, em questões financeiras, junto a SEDUC/AM e ao MEC. A verba injetada nas escolas vem através do Programa Dinheiro Direto na Escola (PDDE). Esse Programa foi criado em 1995, cuja finalidade é prestar assistência financeira às escolas, visando a elevação do desempenho escolar. 
Dentre os programas divulgados pelo MEC para atender ações propostas da política de educação inclusiva financiados pelo PDDE, exemplificamos o Programa Escola Acessível (PEA) que tem por objetivo adequar o espaço físico das escolas, com o intuito de promover a acessibilidade na rede pública de ensino para atender alunos com ou sem deficiência.

Ps profissionais GE1, GE2, GE3 e GE4, gestores das unidades escolares, divergem em seus argumentos da posição dos profissionais GS1 e GS2 em relação, principalmente, a formação continuada dos professores da sala de aula comum, com foco da educação especial. Embora duas das unidades escolares estejam estruturadas com SRM para o atendimento especializado dos alunos com DI, mesmo assim, os gestores dessas escolas compactuam com a opinião dos gestores das escolas sem o AEE sobre a necessidade de formação continuada e específica ao professor da sala de aula comum.

A formação continuada é condição imprescindível para a qualidade do trabalho do professor. É o aperfeiçoamento, em processo contínuo, do conhecimento e necessário para o fazer pedagógico. Quando essa regra na legislação educacional é descumprida afeta o andamento do processo educativo. Pesquisas apontam que ao falar de formação inicial e continuada de professores é um problema reiterado há décadas pela maioria dos estudos sobre inclusão escolar (Pletsch, 2012, p. 156).

No relato desses profissionais, a formação continuada não acontece como afirmado pelos profissionais GS1 e GS2. Existe uma reivindicação por parte desses gestores escolares de maior empenho da SEDUC/AM, através de seu órgão competente, na organização da formação continuada que inclua os professores da sala de aula comum, pois ficou evidenciado nas falas desses gestores que as formações são direcionadas aos professores de AEE. Compactuam com essa posição os profissionais GC1 e GC2, para eles a formação continuada, com foco na educação especial, deve ter maior abrangência, ou seja, oferecendo a todos os professores que trabalham a escolarização do aluno com DI.

\subsection{Inclusão escolar do aluno com DI no Ensino Médio}

Para análise desta categoria consideramos como ponto de partida a Constituição Federal de 1988, quando em seu artigo 205 define a educação como direito de todos, garante o pleno desenvolvimento da pessoa e estabelece a igualdade de condições no acesso e permanência na escola; no artigo 208, III, garante a oferta de AEE pelo Estado (Brasil, 1988).

Para o mesmo fim, nos apropriamos também de informações contidas em dispositivos da LDBEN de 1996, artigo 58 e parágrafos que define o público da educação especial e assegura o atendimento aos alunos com deficiência ao longo da vida; na PNEEPEI de 2008, onde se fundamenta a política nacional de educação na perspectiva inclusiva; e na LBI de 2015 quando aborda sobre o direito à educação inclusiva e de qualidade em todos os níveis de ensino em condições de acesso, permanência, participação e aprendizagem, com oferta de AEE e recursos de acessibilidade que eliminem as barreiras. Todo esse registro é pela reflexão sobre a inclusão escolar dos alunos com DI em escolas comuns do ensino médio (Brasil, 1996; 2008; 2015).

$\mathrm{Na}$ literatura, o diálogo sobre a inclusão escolar do aluno do ensino médio com deficiência intelectual, nas classes comuns, é observado a partir dos vários desafios no processo de aprendizagem, autonomia e cidadania. Começa pela identificação desse aluno e as dificuldades evidenciadas para se conhecer a deficiência e posteriormente encaminhá-lo aos serviços especializados (Veltrone; Mendes, 2011; Pletsch, 2012; Glat, 2012; Valentini; Gomes; Bisol, 2016).

Quando se fala da inclusão escolar cabe relembrar o significado de Educação Inclusiva. Esta como parte no processo escolar em que todas as pessoas, com deficiência ou não, têm o direito à escolarização, devendo ser vista como um processo social da qual está inserida pelas relações de convivência entre os indivíduos do qual faz parte o processo escolar. É uma educação voltada para a formação completa e livre de preconceitos que reconhece as diferenças que são ilimitadas nos seres humanos. A educação inclusiva é divulgada por todas as políticas públicas de educação nacional (Brasil, 1988; 1996).

É o tipo de escola que acompanha o trabalho do professor dando a ele o suporte que necessita para desenvolver melhor o atendimento dos alunos. As propostas de orientação das atividades escolares e as intenções dos educadores relativas à 
inclusão estão registradas em seu Projeto Político Pedagógico (PPP). Nesse documento ficam estabelecidas quais redes de apoio serão necessárias para o atendimento aos alunos com deficiência, no caso, com deficiência intelectual (Brasil, 1996).

Ao aluno desse segmento deve ser oferecido recursos diferenciados indispensável ao seu aprendizado, bem como adaptações físicas do ambiente escolar e professores especializados. Dependendo do caso, o aluno, pela regra jurídica, além de frequentar a escola comum inclusiva, deverá também frequentar no contraturno uma escola especial que funcionará como um centro de apoio e complementação de sua formação (Brasil, 1996). Nesse caso, no processo de inclusão, no sentido mais consistente da palavra, o recomendável seria o aluno que necessita de AEE receber esse serviço na própria escola do ensino regular na qual estuda.

Categorizando as respostas dos profissionais entrevistados GS1, GS2, GC1, GC2, GE1, GE2, GE3 e GE4, nessa última temática abordada, a formação continuada dos professores se destaca como sendo um dos maiores desafios da escola comum no processo de inclusão, pois na perspectiva inclusiva a capacitação dos professores da sala de aula comum é imprescindível na escolarização do aluno com Deficiência Intelectual.

A preocupação que reflete na fala dos agentes entrevistados é a capacitação e formação continuada dos professores da sala de aula comum como sendo fundamental para lidar com esse público, bem como as adaptações e os equipamentos que forem necessários para o aprendizado. Infelizmente os professores da sala de aula comum ainda estão distantes de receber formações que os preparem para lidar com as diferenças e particularidades de cada aluno, bem como existem muitas escolas que não disponibilizam das Salas de Recursos Multifuncionais (SRM), portanto, sem oferta de AEE que é um direito constitucional do aluno.

Em termos de recursos humanos, é prevista a formação de capacitação do professor que atua na sala de aula comum e a especialização do professor que atua no AEE, considerando o trabalho colaborativo entre ambos, pois a interlocução entre o professor do AEE e o professor da classe comum traduz-se na essência do processo de desenvolvimento inclusivo da escola (Brasil, 2013).

O Amazonas acompanhou publicou a Resolução no 155/2002 do CEE/AM que regulamentava normas para a oferta de Educação Especial no sistema de ensino do Estado, sendo revogada pela Resolução no 138/2012, em vigor até a presente data. No artigo 20, alínea f, dessa Resolução está garantido a "Formação Continuada, em Educação Especial, para os profissionais da educação, visando a implementação da inclusão escolar" (Amazonas, 2012).

Pereira e Marques (2018, p. 8) apontam a reivindicação dos professores sobre a falta de apoio dos governantes em fazer vigorar as leis voltadas para a inclusão, onde a inquietude desses profissionais fluem "principalmente na formação dos profissionais da escola porque são eles que lidam com esses alunos na sala de aula".

No cenário da educação inclusiva das escolas públicas de ensino médio do Amazonas, em relação as políticas educacionais inclusivas implementadas pela SEDUC/AM, em escolas de Manaus, para atender, dentro das regras da inclusão, o aluno com DI nessa etapa da educação básica, o que se observa é a legislação a passos largos em dispositivos legais, que são os pilares de sustentação criados para atender esse público, porém a aplicabilidade dessa teia de leis, decretos, tratados parece distante de ser efetivamente concretizada, ou seja, a adoção de leis ou a adesão a tratados não serão suficientes se não houver compromisso individual e coletivo, através de ações afirmativas, para esse fim.

Como principais resultados verificamos que as políticas educacionais, através de programas, projetos, ações e serviços, desenvolvidos pela SEDUC/AM para o público do Ensino Médio, em Manaus/AM, estão chegando às escolas para atender a todos os alunos como determina o corpus da legislação nacional e estadual, o que não significa se está alcançando os alunos com DI e promovendo mudanças significativas no seu processo de escolarização. 
O desafio da escola pode surgir a partir do momento em que se fizer cumprir os princípios da inclusão evitando a manutenção da prática pedagógica homogênea, enquadrando o aluno com DI em procedimentos didáticos universais, desconsiderando as diferenças.

Especificamente, através do Programa Escola Acessível, de competência federal, está sendo possível reestruturar as escolas, que aderem ao Programa e são contempladas com verba federal para a infraestrutura, os recursos disponibilizados às escolas vinculadas ao Programa de Salas de Recursos Multifuncionais e o AEE para atender as necessidades dos alunos com DI ou outras deficiências.

Por fim, a inquietude dos coordenadores distritais e gestores escolares na lenta efetivação das políticas inclusivas para esse público, principalmente pela necessidade da implantação de novas SRM e ampliação do AEE, bem como agilização para a imprescindível formação continuada dos professores das classes comuns, com foco em propostas inclusivas que contribua no atendimento desse público que tem DI e está cursando o Ensino Médio.

Contudo, o processo da educação inclusiva está evoluindo gradativamente nas escolas estaduais de ensino médio, em Manaus/AM, apesar dos desafios ainda estarem muito presente na luta pela eliminação das barreiras de acessibilidade que representam um grande desafio para todos os alunos, com ou sem deficiência.

\section{Conclusão}

Pois, de fato, no realce da educação em direitos humanos, no campo da educação especial, a inclusão das pessoas com deficiência intelectual nas escolas do ensino regular está resguardada na legislação nacional que tem como documento maior a Constituição Federal de 1988 e a LDBEN de 1996, além da PNEEPEI de 2008 e da LBI de 2015, entre outros, para sustentar que o Brasil é um país inclusivo.

A educação inclusiva não significa equipar as escolas para torná-las acessíveis, mas numa abordagem proativa para que seja possível a identificação e eliminação das barreiras de acessibilidade que estão presentes nos ambientes escolares comuns, dificultando o acesso e oportunidades aos estudantes com deficiência intelectual que buscam pela escolarização com equidade garantida na legislação brasileira.

A inclusão do aluno com deficiência intelectual no ensino médio das escolas públicas estaduais, no contexto nacional, em documentos oficiais do MEC, representa uma tímida proporcionalidade do acesso nessa etapa da educação básica. Nas escolas estaduais de ensino médio em Manaus/AM, o efeito é o mesmo sendo evidenciado em documentos oficiais da SEDUC/AM. Trata-se de uma realidade excludente e desigual para esse público no contexto atual da educação brasileira. Considerando, também, que a inclusão do aluno com DI no Ensino Médio é uma temática ainda pouco explorada nas pesquisas acadêmicas do país.

A possibilidade em viabilizar melhorias na escolarização do aluno com DI no ensino médio, através da implementação de políticas educacionais, nos motivou investigar como vem se processando a inclusão desses alunos nessas atividades realizadas em escolas públicas estaduais no município de Manaus/AM.

Nessa expectativa, vimos a relevância desse estudo considerando as seguintes proposições: i) a necessidade de entender o afunilamento existente nas matrículas dos alunos com DI para o acesso ao ensino médio apontado pelos censos; ii) o entendimento do binômio Deficiência Intelectual e Ensino Médio. A DI, pela dificuldade do aluno avançar nas etapas mais elevadas da educação escolar e o Ensino Médio, pelos entraves acumulados em sua historicidade; iii) a discussão sobre as políticas públicas educacionais inclusivas e possibilidades que elas trazem na implementação de programas, projetos e ações desenvolvidos pela SEDUC/AM para atender o aluno com DI, no Ensino médio; iv) a pouca pesquisa voltada à inclusão do aluno com DI no Ensino Médio; v) a pouca pesquisa realizada por profissionais da educação com abordagem sobre essa 
temática no contexto Amazônico; e, vi) a contribuição do estudo para o desenvolvimento de novas pesquisas direcionadas ao ensino médio regular, envolto no aluno com DI e suas especificidades em aprender.

Esta pesquisa possibilitou que os gestores institucionais refletissem e debatessem, dentro de suas funções e responsabilidades, sobre o cotidiano da escola considerando os entraves e desafios, em relação ao processo da inclusão do aluno da educação especial, especificamente, o aluno com Deficiência Intelectual evidenciado neste estudo.

Cabe, aqui, uma reflexão sobre as nossas indagações terem sido lançadas aos gestores institucionais, uma vez que a nossa pesquisa tem enfoque na Dialética e, a beleza deste método de diálogo está em mostrar as contradições de ideias possibilitando a criação de novos conhecimentos. Esse foi um desafio vencido, a partir do momento em que os argumentos dos gerentes institucionais se contrapuseram, evidenciando a contradição de ideias. Por se tratar de servidores em cargos comissionados, portanto, com maior probabilidade em defender os interesses de quem detém o poder, no entanto, os posicionamentos revelam uma certa inquietude pelo não oferecimento e cumprimento, de modo efetivo, de políticas educacionais inclusivas para o público da educação especial. Essa posição mediadora desses agentes, entre governo e escola, e de insatisfação com as questões educacionais direcionadas aos alunos com DI, reflete de modo positivo quando se pensa nos princípios da gestão democrática e no trabalho colaborativo idealizando a escola para todos.

Ademais, os programas, projetos, ações e serviços oferecidos pela SEDUC/AM para o atendimento dos alunos com DI no ensino médio, são encaminhados às escolas via coordenadorias. O envolvimento do aluno com DI nessas atividades pedagógicas, seja de competência federal ou estadual, com foco de atuação em avalição, currículo, competição e prêmio, ou outros, passa a ser de responsabilidade da escola. No entanto, a escola para obter êxito nesse processo necessita que a intencionalidade da SEDUC/AM se efetive, ampliando a formação continuada do professor com foco na educação inclusiva; na funcionalidade das SRM e no AEE integrado às atividades desenvolvidas nas classes comuns; e a parceria com a família, esta buscada pela escola, no compartilhamento das responsabilidades em relação a escolarização do aluno com DI. Esse tripé, se implementado efetivamente, poderá sustentar e consolidar a inclusão desses alunos nas escolas estaduais de ensino médio em Manaus.

Nesse contexto, a SEDUC/AM traz em seu discurso, referenciado nos documentos legais, a implantação de ações inclusivas para o público da educação especial nas escolas estaduais, oferecendo formação de professores, oferta de serviços pedagógicos diferenciados e principalmente pelos $90 \%$ dos 62 municípios do estado estarem com SRM implantadas o que reflete em ações positivas e engrandecedoras em se tratando de educação escolar inclusiva, no entanto, para que esses programas, projetos ações ganhem corpo nas escolas, se faz necessário maior integração entre as coordenadorias que atuam na coordenação do ensino médio, na coordenação da educação especial e as distritais num trabalho colaborativo que possa suprir a necessidade da escola que atende o aluno envolto nesse complexo binômio: Ensino Médio e Deficiência Intelectual.

Por outro lado, a SEDUC/AM precisa colocar essas ações em transparência, divulgando-as no Sítio Eletrônico da instituição, de modo que a comunidade escolar do estado e sociedade em geral possam ter conhecimento sobre a periodicidade da formação continuada dos profissionais da educação que atuam nas classes comuns e no AEE, bem como da funcionalidade e resultado dos projetos pedagógicos realizados nas escolas com ou sem SRM implantadas e a oferta dos serviços de atendimento diferenciado como o hospitalar, o domiciliar e o psicossocial disponibilizados para as escolas estaduais do Amazonas. É importante, também, a SEDUC/AM, através de seus departamentos e coordenadorias, está em alerta aos programas oferecidos pelo governo federal, incentivando as escolas na adesão e orientando-as no processo de implementação. A escola participa desde que motivada.

Por fim, espera-se que este estudo possa ter contribuído como reflexão aos gestores institucionais da SEDUC/AM em relação a importante tarefa a eles delegada que é a organização de políticas educacionais e inclusivas a serem implementadas nas escolas estaduais de Manaus. É recomendável aprofundar pesquisa dentro dessa temática a fim de registrar avanços na 
aplicabilidade das diretrizes específicas sobre inclusão do aluno com DI no ensino médio, garantindo que as recomendações na Declaração Universal dos Direitos Humanos e a Convenção dos Direitos das Pessoas com Deficiência da ONU deixem de ser uma ilustração no corpo das Leis nacionais e estaduais e passem a ser respeitadas como um referencial de Direitos Humanos nas políticas públicas educacionais e inclusivas no Estado do Amazonas.

\section{Referências}

Amazonas. (2019). Censo Escolar. SEDUC/DPGF/GEPES/CEST (MEC/INEP). Série Histórica - Número de matrículas de alunos do ensino médio com deficiência intelectual. Gerência de Pesquisa e Estatística - GEPES/SEDUC.

Amazonas. (2019b). Governo do Estado. SEAD/AM. Relatório de Transição/Versão Consolidada. Mensagem do governador Wilson Lima (2019-2022). 2019. Em: http://www.amazonas.am.gov.br/content/uploads/2020/02/MSG_GOV_2019_2020-WEB.pdf

Amazonas. (2019c). Lei Delegada $n^{\circ} 122$ de 15 de Outubro de 2019. Dispõe sobre a organização administrativa do Poder Executivo Estadual. Diário Oficial do Estado do Amazonas, de 15 de outubro de 2019, Poder 2019. http://www.seas.am.gov.br/leis/\#: :text=LEI\%20DELEGADA\%20No.122\%2F2019,de\%20Estado\%20da\%20Assist\%C3\%AAncia\%20Social.

Amazonas. (2019d). Lei Delegada $n^{o} 3.642$ de 26 de julho de 2011. Altera a Lei Delegada $\mathrm{n}^{\mathbf{o}} 78$ de 18 de maio de 2007.2019. https://sapl.al.am.leg.br/media/sapl/public/normajuridica/2011/8097/8097_texto_integral.pdf\#: :text=78\%2C\%20de\%2018\%20de\%20maio\%20de\%202007\% 2C\%20que\%20\%22DISP\%C3\%95E,a\%20seguinte\%20reda\%C3\%A7\%C3\%A3o\%3A\%20\%E2\%80\%9CArt.

Amazonas. (2012). Resolução no 138, de 16 de outubro de 2012 - Aprova normas regulamentares para a oferta de educação especial no Sistema de Ensino no Estado do Amazonas. Conselho Estadual de Educação do Amazonas (CEE/AM), <http://www.cee.am.gov.br/?option=com_phocadownload\&view=category\&id=23:2012\&Itemid=194>

Amazonas. (2020). Secretaria de Educação. Portal SEDUC: Educação que Transforma. 2020. http://www.educacao.am.gov.br/

Bardin, L. (2011). Análise de conteúdo. Edições.

Brasil. (1988). Constituição da República Federativa do Brasil de 1988. Brasília: DF: Presidência da República. 2016. http://www.planalto.gov.br/ccivil_03/Constituicao/Constituiçao.htm

Brasil. (2011). Decreto $n^{\circ} 7.611$, de 17 de novembro de 2011. Dispõe sobre a educação especial, o atendimento educacional especializado e revoga o Decreto $\mathrm{n}^{\circ}$ 6.571, de 17 de setembro de 2008. Diário Oficial da União, Brasília, DF, 18 nov. 2011a. Seção 1, p. 12

Brasil. (2015). Instituto Nacional de Estudos e Pesquisas Educacionais Anísio Teixeira - INEP/MEC/DAEB. Relatório Pedagógico: ENEM 2011-2012. Brasília, DF: INEP, 2015. http://portal.inep.gov.br/documents/186968/484421/Relat\%C3\%B3rio+Pedag\%C3\%B3gico+Enem+2011-2012/b29257e3-2a6c44a3-992a-02130c379ba9?version=1.1

Brasil. (2017). Lei $n^{o} 13.415$, de 13 de fevereiro de 2017, Altera as Leis nos 9.394, de 20 de dezembro de 1996, que estabelece as diretrizes e bases da educação nacional, e 11.494, de 20 de junho 2007, que regulamenta o Fundo de Manutenção e Desenvolvimento da Educação Básica e de Valorização dos Profissionais da Educação, a Consolidação das Leis do Trabalho - CLT, aprovada pelo Decreto-Lei no 5.452, de 1o de maio de 1943, e o Decreto-Lei no 236, de 28 de fevereiro de 1967; institui a Política de Fomento à Implementação de Escolas de Ensino Médio em Tempo Integral. 2017. http://www.planalto.gov.br/ccivil_03/_ato2015-2018/2017/lei/L13415.htm

Brasil. (2019). MEC/INEP. Instituto Nacional de Estudos e Pesquisas Educacionais Anísio Teixeira. Resumo Técnico: Censo da Educação Básica 2018 [recurso eletrônico]. - Brasília: Instituto Nacional de Estudos e Pesquisas Educacionais Anísio Teixeira, 2019.

Brasil. (2009). Ministério da Educação. CNE/CEB. Resolução $n^{o} 4$, de 2 de outubro de 2009, que institui as Diretrizes Operacionais para o Atendimento Educacional Especializado na Educação Básica, modalidade Educação Especial. 2009. http://portal.mec.gov.br/dmdocuments/rceb004_09.pdf.

Brasil. (2001). Ministério da Educação. Diretrizes nacionais para a educação especial na educação básica / Resolução CNE/CEB no 2 , de 11 de setembro de 2001. Secretaria de Educação Especial - MEC; SEESP, 2001. http://portal.mec.gov.br/cne/arquivos/pdf/CEB0201.pdf

Brasil. (2018). Ministério da Educação. INEP - Instituto Nacional de Estudos e Pesquisas Educacionais Anísio Teixeira. Censo Escolar da Educação Básica, 2018. Em: http://inep.gov.br/censo-escolar

Brasil. (2016). Ministério da Educação. INEP/MEC. Secretaria de Educação Básica/Diretoria de Currículos e Educação Integral/Coordenação Geral de Ensino Médio. Programa Ensino Médio Inovador. 2016. http://portal.mec.gov.br/docman/novembro-2016-pdf/50311-documento-orientador-adesao-20162017$\mathrm{pdf} /$ file.

Brasil. (2014). Ministério da Educação (MEC). SECADI/DPEE. Nota Técnica $n^{\circ} 04$ de janeiro de 2014. Orientação quanto a documentos comprobatórios de alunos com deficiência, transtornos Globais do desenvolvimento e altas habilidades/superlotação no Censo Escolar. 2014. http://portal.mec.gov.br/index.php?option=com_docman\&view=download\&alias=17237-secadi-documento-subsidiario-2015\&Itemid=30192

Brasil. (2011). Ministério da Educação (MEC). SECADI/SEESP/GAB. Nota Técnica $n^{o} 06$ de 11 de março de 2011 . Avaliação do estudante com deficiência intelectual. 2011. http://portal.mec.gov.br/index.php?option=com_docman\&view=download\&alias=17237-secadi-documento-subsidiario2015\&Itemid $=30192$

Brasil. (2010). Ministério da Educação (MEC). SECADI/SEESP/GAB. Nota Técnica $n^{\circ} 19$ de 08 de setembro de 2010. Profissionais de apoio para alunos com deficiência e transtornos globais do desenvolvimento matriculados nas escolas comuns da rede pública de ensino. 2010. http://portal.mec.gov.br/index.php?option=com_docman\&view=download\&alias=17237-secadi-documento-subsidiario-2015\&Itemid=30192 
Brasil. (2015). Ministério da Educação (MEC). SECADI/DPEE. Nota Técnica $n^{\circ} 20$ de 18 de março de 2015. Orientações aos sistemas de ensino visando ao cumprimento do artigo $7^{\circ}$ da Lei $\mathrm{n}^{\circ} 12.764 / 2012$ regulamentada pelo Decreto $\mathrm{n}^{\circ} \quad 8.368 / 2014 . \quad 2015$. gov.br/index.php?option=com_docman\&view=download\&alias=17213-nota-tecnica-20-orientacao-aplicacao-multa-20mar\&Itemid=30192

Brasil. (2013). Ministério da Educação (MEC). SECADI/DPEE. Nota Técnica ${ }^{\circ} 123$ de 24 de setembro de 2013. Resposta ao requerimento $n^{\circ} 3325 / 2013$ de Autoria da Deputada Mara Gabrilli. Referência: Ofício $1^{\circ} \quad \mathrm{Sec} / \mathrm{RI} / \mathrm{E} / \mathrm{n}^{\circ} \quad 907 / 2013.2013$. http://portal.mec.gov.br/index.php?option=com_docman\&view=download\&alias=17237-secadi-documento-subsidiario-2015\&Itemid=30192

Brasil. (2013). Ministério da Educação. SEB/DCEI/CGEM. Programa Ensino Médio Inovador. Documento Orientador 2013. Pacto Nacional pelo Fortalecimento do Ensino Médio. 2013. http://portal.mec.gov.br/index.php?option=com_docman\&view=download\&alias=13249-doc-orientador-proemi2013novo-pdf\&category_slug=junho-2013-pdf\&Itemid=30192.

Brasil. (2011). Ministério da Educação. SECADI. Manual do Programa Escola Acessível. 2011. http://portal.mec.gov.br/busca-geral/194-secretarias112877938/secad-educacao-continuada-223369541/17428-programa-escola-acessivel-

novo\#: :text=Como\%20acessar\%3A\%20As\%20escolas\%20contempladas,planejamento\%20de\%20utiliza\%C3\%A7\%C3\%A3o\%20dos\%20recursos.

Brasil. (2008). Ministério da Educação - Secretaria de Assuntos Estratégicos da Presidência da República - SAE/PR. Reestruturação e Expansão do Ensino Médio no Brasil. Brasília, jul. 2008. http://portal.mec.gov.br/seb/arquivos/pdf/2008/interministerialresumo2.pdf.

Brasil. (2014). Ministério da Educação. SEB/DAGE. Pacto Nacional pela Alfabetização na Idade Certa: Educação Inclusiva / Ministério da Educação, Secretaria de Educação Básica, Diretoria de Apoio à Gestão Educacional. - Brasília: MEC, SEB, 2014. P. 96.

Brasil. (2019). Ministério da Educação. SEMESP/DEE. Diretoria de Acessibilidade, Modalidade, Inclusão e Apoio a Pessoas com Deficiência. PNEE. 2019. https://drive.google.com/file/d/1qV5COC5gga2DekWLV-CcJZUpp6AEKqgk/view.

Brasil. (1994). Política Nacional de Educação Especial. Brasília: MEC/SEESP. 1994. Em: https://inclusaoja.files.wordpress.com/2019/09/polc3adticanacional-de-educacao-especial-1994.pdf.

Brasil. (2008). Política Nacional de Educação Especial na Perspectiva da Educação Inclusiva. Brasília: MEC/Seesp, 2008. Organização das Nações Unidas: http://www.onu-brasil.org.br; Presidência da República Federativa do Brasil. 2008. http://www.planalto.gov.br.

Brasil. (2011). Resolução $n^{\circ} 27$ de 2 de junho de 2011. MEC/CD/FNDE. Dispõe sobre a destinação de recursos financeiros, nos moldes e sob a égide da Resolução n ${ }^{\circ}$ 17, de 19 de abril de 2011, a escolas públicas municipais, estaduais e do Distrito Federal da educação básica, com matrículas de alunos público alvo da educação especial em classes comuns do ensino regular, que tenham sido contempladas com salas de recursos multifuncionais em 2009 e integrarão o Programa Escola Acessível em 2011. https://www.fnde.gov.br/index.php/acesso-a-informacao/institucional/legislacao/item/3450-resolu\%C3\%A7\%C3\%A3ocd-fnde-n\%C2\%BA-27-de-2-de-junho-de-

2011\#: :text=Disp\%C3\%B5e\%20sobre\%20a\%20destina\%C3\%A7\%C3\%A3o\%20de,ensino\%20regular\%2C\%20que\%20tenham\%20sido

Brasil. (2018). Resolução n ${ }^{\circ}$ 3, de 21 de novembro de 2018, Ministério da Educação. CNE/CEB. Atualiza as Diretrizes Curriculares Nacionais para o Ensino Médio. Diário Oficial da União, Brasília, 22 de novembro de 2018, Seção 1, pp.21-24.

Bueno, J. G. S. (2016). O atendimento educacional especializado (AEE) como programa nuclear das políticas de educação especial para a inclusão escolar. Tópicos Educacionais: sentidos da inclusão. Recife- PE, 22(1), 68 a 87.

Dambros, A. R. T.; \& Mori, N. N. R. (2015). Inclusão escolar na região Norte do Brasil: Um mapeamento do atendimento educacional especializado nos estados do Amazonas, Rondônia e Pará. Interfaces Científicas - Educação, Aracajú, 3(3), 35-45

Dias, S. S. de \& Oliveira M-C. S. L. (2012). Inclusão escolar de pessoas com deficiência intelectual: linguagem e construção de sentido. In A.M.U.A Branco \& M-C. S. L. de Oliveira (Org.). Diversidade e cultura da paz na escola: contribuições da perspectiva sociocultural. Mediação, 2012

Gutberlet, J. (2002). Zoneamento da Amazônia: uma visão crítica. Amazônia Brasileira II. Estudos Avançados. Print version http://www.scielo.br/scielo.php?script=sci_arttext\&pid=S0103-40142002000300013.

Instituto Unibanco. (2016) Panorama dos Territórios (Amazonas), 2016. https://observatoriodeeducacao.org.br/wpcontent/uploads/2017/03/PanoramasAMAZONAS.pdf.

Oliveira, I. (2015). A. de. Desafios da didática diante das políticas de inclusão. Crítica Educativa (Sorocaba/SP), 1(2), 110-126.

ONU. (2006). Convenção sobre os direitos das pessoas com deficiência (2006): aprovada pela Assembleia Geral da ONU em dezembro de 2006.

ONU. (2011). Organização das Nações Unidas. Ano Internacional da Juventude - 12 de agosto de 2010 - 12 de agosto de 2011. Tema: Diálogo e Compreensão Mútua (Tradução: UNIC Rio, 2010). 2011. http://unicrio.org.br/juventude2010-2011/

Pereira, D. D.; \& Marques, S. M. F. (2018). O diálogo do currículo de formação de professores com a prática no atendimento educacional especializado-AEE na mesorregião do Baixo Amazonas. UEPA. III Congresso Internacional de Educação Inclusiva - III CINTEDI \& a III Jornada Chilena Brasileira sobre Educação Inclusiva e Direitos Humanos. 29 a 31 de agosto. Paraíba. Ago. 2018.

Pletsch, M. D., \& Glat, R. (2012). A escolarização de alunos com deficiência intelectual: uma análise da aplicação do Plano de Desenvolvimento Educacional Individualizado. Linhas Críticas, 18(35), 193-208, Universidade de Brasília (UNB), Brasília, DF

Rek, M. (2015). Os modelos de administração pública e reflexos à qualidade na gestão administrativa brasileira. Revista Âmbito Jurídico, http://www.ambitojuridico.com.br/site/?n_link=revista_artigos_leitura\&artigo_id=14742

UNESCO. (1990). Conferência Mundial sobre Educação para Todos. Declaração mundial sobre educação para todos e Plano de ação para satisfazer as necessidades básicas de aprendizagem. Jomtien: Tailândia, http://www.direitoshumanos.usp.br/index.php/Direito-a-Educa\%C3\%A7\%C3\%A3o/declaracaomundial-sobre-educacao-para-todos.html 
Research, Society and Development, v. 11, n. 2, e17311225678, 2022

(CC BY 4.0) | ISSN 2525-3409 | DOI: http://dx.doi.org/10.33448/rsd-v11i2.25678

UNESCO. (1994). Declaração de Salamanca. Sobre Princípios, Políticas e Práticas na Área das Necessidades Educativas Especiais: http://portal.mec.gov.br/seesp/arquivos/pdf/salamanca.pdf

Valentini, C.; Gomes, R., \& Bisol, C. (2016). Inclusão de estudantes com deficiência intelectual: uma revisão sistemática da literatura. Revista Teias. Observatório de educação especial e inclusão escolar, 17(46), 125-142.

Veltrone, A. A., \& Mendes, E. G. (2011). Percepções dos alunos com deficiência intelectual sobre sua matrícula na classe especial e classe comum. Revista Eletrônica de Educação. 5(2), 59-81. 